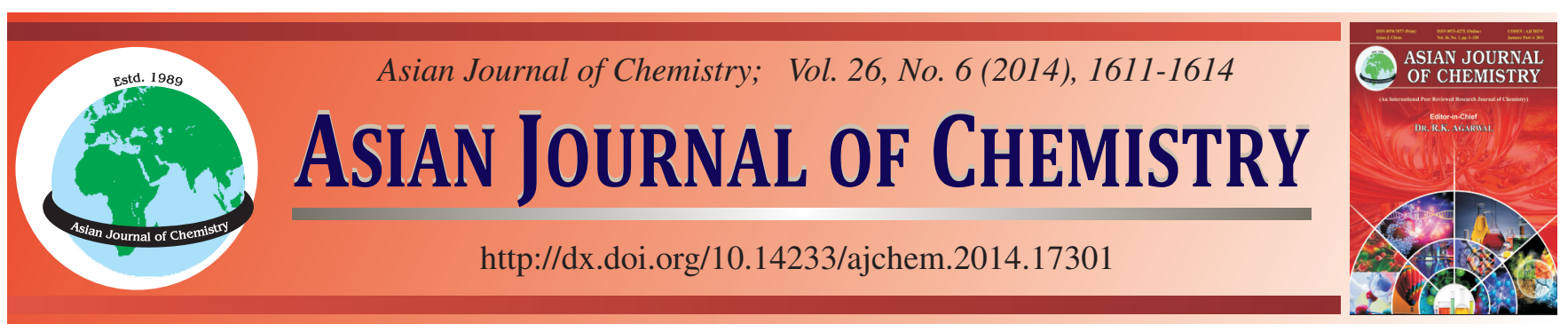

\title{
Assembly of ZSM-5 Zeolite on Natural Fiber $\dagger$
}

\author{
Yong Hwa Lee, Keon Hee Park and Seung Kyu ParK*
}

Department of Chemical Engineering, Hoseo University, Asan 336-795, Republic of Korea

*Corresponding author: Fax: +82 41 5405758; Tel: +82 41 5409686; E-mail: skpark@ hoseo.edu

\begin{abstract}
Some materials such as nano silver and nano transition metals impregnated zeolite materials may have extraordinary properties such as antibacterial and antivirus. But they might cause the inhalation toxicity, since the size and surface area are recognized as important determinants for toxicity to human. We report the ZSM-5 zeolite anchored kapok fiber synthesized by hydrothermal reaction. We suggest that self assembly of such functional materials to natural fiber can reduce the inhalation risk and maximize the functionality of nano materials. To get the clear and smooth surface of the hollow fiber, solvent and acid treatment process had been adopted to remove the lignin and wax layer. The hollow kapok fibers were applied as a template in the hydrothermal reaction for preparation of ZSM-5 zeolite anchored Kapok fiber. The Kapok-ZSM-5 composites were confirmed and characterized by SEM, XRD, TG-DTA and FTIR analysis.
\end{abstract}

Keywords: ZSM-5 zeolite, Kapok, Hollow, Hydrothermal reaction, Template synthesis.

\section{INTRODUCTION}

After the historical publication of ordered mesoporous molecular sieves by a liquid crystal template synthesis method ${ }^{1}$, many newly designed nano-structured materials have been introduced by various kinds of template synthesis or fabrication during last two decades ${ }^{2-4}$. Among them, porous carbon materials have attracted considerable attention because of their remarkable properties such as high specific surface area, large pore volume, chemical inertness and good mechanical stability, which propose great potentials in many areas of modern science and technology including water and air purification, gas separation, catalysis, chromatography, energy storage and electrode for battery and fuel cell ${ }^{4-8}$. Using an organic component as a template has accelerated development of new zeolites ${ }^{9}$. The initial driving force for use of organic cations such as alkyl ammonium was to synthesize a zeolite material with a larger intracrystalline pore channel system than X or Y type zeolites which have been used extensively in catalytic cracking processes $^{9-11}$. A wider pore zeolite would crack more of the larger hydrocarbons in petroleum ${ }^{10-12}$. Some materials such as nano silver and nano transition metals impregnated zeolite materials have attracted considerable attention since they show extraordinary properties such as antibacterial and antivirus ${ }^{13-16}$. But they might cause the inhalation toxicity, since the size and surface area are recognized as important determinants for toxicity to human ${ }^{17}$. Sometimes, the nano sized materials show the unique properties in the nano scale, but, they lose the activity during the fabrication to macro scale. The organization of nano materials to various substrates without any extinction of their nano scaled properties and inhalation problems remain to be studied. Self-assembly of nano materials to substrates allows materials to be designed with hierarchical order and complexity that mimics those seen in biological systems ${ }^{18}$. The growth of 2D arrays of uniformly aligned silicalite- 1 crystals on glass oriented perpendicular to the substrate plane have been reported ${ }^{18}$. The aligned polyurethane films as matrices have been applied for the manipulation of nano materials ${ }^{18}$.

Recently, many interests in natural fiber reinforced polymer composites materials are rapidly growing both in terms of industrial applications and fundamental research ${ }^{19}$. They are renewable, low cost, recyclable and biodegradable. Kapok fiber is natural and has a shape of round microtube with smooth surface and thin wall. Chemically, Kapok fiber consists mainly of cellulose and an inert plastic-like material called lignin ${ }^{20}$. In this study, the syntheses of various mesoporous material and nano silica ball material anchoring on the Kapok surface have been studied. In this research we report the ZSM-5 zeolite anchored Kapok fiber synthesized by hydrothermal reaction. To get the clear and smooth surface of the hollow fiber, solvent

†Presented at The 7th International Conference on Multi-functional Materials and Applications, held on 22-24 November 2013, Anhui University of Science \& Technology, Huainan, Anhui Province, P.R. China 
and acid treatment process had been adopted to remove the lignin and wax layer. The hollow Kapok fibers were applied as a template in the hydrothermal reaction for preparation of ZSM-5 zeolite anchored Kapok fiber.

\section{EXPERIMENTAL}

The Kapok was a product of Thailand. The fiber has an hollow tubular structure with average internal diameter by 12 $16 \mathrm{~mm}$. The thickness of the hollow tube was $2 \mathrm{~mm}$. Soxhlet washing of Kapok by hexane solution for $1 \mathrm{~h}$ was conduct to wash the internal wax and lignin components. The fibers were dried at room temperature.

Synthesis of ZSM-5-Kapok composites: For the modification of Kapok surface, the soxhlet washed Kapok was soaked in cetyl trimethyl ammonium bromide (CTAB, $1 \%$ solution) or sodium dodecyl sulphate (SDS, $1 \%$ solution) and then dried at room temperature overnight (Fig. 1). The surface modified Kapok fiber was placed into an aluminum silicate gel. The aluminum silicate gel was made by mixing of $7.83 \mathrm{Na}_{2} \mathrm{O}$ : 1TPABr: $3000 \mathrm{H}_{2} \mathrm{O}:(0.25-2.00) \mathrm{Al}_{2} \mathrm{O}_{3}: 100 \mathrm{SiO}_{2}$. Table-1 shows the aluminum silicate gel composition applied for the experiment. ZSM-5 zeolite was hydrothermally synthesized using tetrapropylammonium bromide (TPABr) as the organic template ${ }^{21}$. After stirring for $2 \mathrm{~h}$, the $\mathrm{pH}$ of the reaction mixture was adjusted to 11 and stirred for another $12 \mathrm{~h}$. The gel was then placed in a stainless steel pressure vessel lined with teflon or autoclave reactor and heated at $150-185^{\circ} \mathrm{C}$ for $24 \mathrm{~h}$. The autoclave was then cooled and the solid product was centrifuged at 4,000rpm for $0.5 \mathrm{~h}$ and filtered and then washed with boiling deionized water and dehydrated at $60{ }^{\circ} \mathrm{C}$ for one day (Table-1).

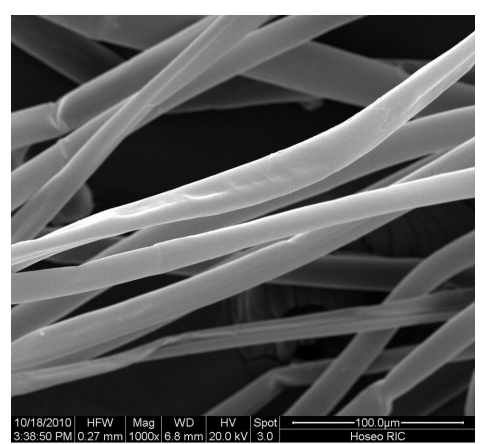

Fig. 1. SEM image of Kapok fiber after soxhlet washing

\begin{tabular}{|c|c|c|c|c|}
\hline \multicolumn{5}{|c|}{$\begin{array}{c}\text { TABLE-1 } \\
\text { PREPARATION AND TREATMENT OF SAMPLES }\end{array}$} \\
\hline $\begin{array}{l}\text { Sample } \\
\text { No. }\end{array}$ & $\begin{array}{c}\text { Temp. } \\
\left({ }^{\circ} \mathrm{C}\right)\end{array}$ & $\begin{array}{l}\mathrm{Si} / \mathrm{Al} \\
\text { ratio }\end{array}$ & $\begin{array}{l}\text { Aging } \\
\text { time }(\mathrm{h})\end{array}$ & Kapok Per-treatment \\
\hline 1 & \multirow{3}{*}{150} & 25 & \multirow{9}{*}{0} & \multirow{9}{*}{ CTAB } \\
\hline 2 & & 100 & & \\
\hline 3 & & 200 & & \\
\hline 4 & & 25 & & \\
\hline 5 & 175 & 100 & & \\
\hline 6 & & 200 & & \\
\hline 7 & \multirow{3}{*}{185} & 25 & & \\
\hline 8 & & 100 & & \\
\hline 9 & & 200 & & \\
\hline 10 & \multirow{3}{*}{150} & \multirow{3}{*}{25} & 48 & $1 \mathrm{~N} \mathrm{NaOH}+\mathrm{SDS}$ \\
\hline 11 & & & 0 & \multirow{2}{*}{$1 \mathrm{~N} \mathrm{NaOH}+\mathrm{SDS}+$ Sonication } \\
\hline 12 & & & 48 & \\
\hline
\end{tabular}

Characterization: The Kapok-ZSM-5 composites were examined with SEM (FEI Quanta 200) at $25 \mathrm{kV}$ and 20,000 magnifications. XRD patterns of the composites were recorded on a Philips PW 1840 diffractometer using $\mathrm{CuK}_{\alpha}$ radiation (40 kV and $25 \mathrm{mV}$ ). The composites were well characterized by Fourier transform infrared spectroscopy (JASCO FTIR-4200) using $\mathrm{KBr}$ self-supported pellet technique. Thermal behavior of the sample was identified by thermogravimetric and differential thermal analysis (TG-DTA, LINSEIS STA PT-1600) performed under a nitrogen atmosphere over a temperature range of room temperature to $900{ }^{\circ} \mathrm{C}$ at a heating rate of $5{ }^{\circ} \mathrm{C} /$ min. The specific surface area was evaluated using the standard Brunauer-Emmett-Teller (BET) method.

\section{RESULTS AND DISCUSSION}

Soxhlet washing of Kapok by hexane solution for $1 \mathrm{~h}$ was conducted to wash the internal wax and lignin components. The Kapok had a hollow fiber structure with external diameter of 12-16 mm (Fig. 1). The surface of Kapok fiber after soxhlet washing is relatively smooth. Two possible methods for ZSM5 anchoring on Kapok fiber can be considered as shown in Fig. 2.

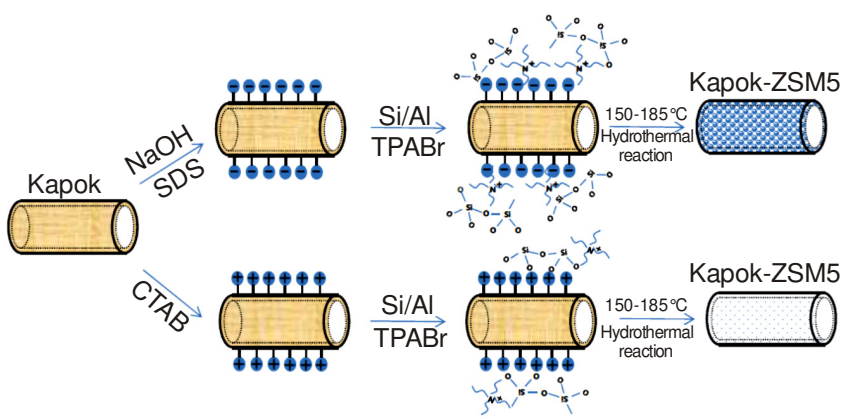

Fig. 2. Schematic diagram for the synthesis of Kapok-ZSM-5

One is the way covered by cationic surfactant such as cetyl trimethyl ammonium bromide and the other is the way covered by anionic surfactant such as sodium dodecyl sulphate. To improve the negative charge, alkali application and ultrasonication were paralleled during the SDS treatment. Since Kapok fiber is highly hydrophobic, hydrocarbon chain of the surfactants can be oriented to the surface. Consequently, the surface can be charged by polar surfactant head groups and then ZSM-5 complex on the Kapok fiber can be formed due to interaction between the charged surface and charged template agent. ZSM-5 can be formed either in the bulk phase of the reaction or on the surface of the Kapok. Most of the ZSM-5 materials were anchored on the surface of Kapok that suggests formation of ZSM-5 on Kapok fiber seems favorable at the treatment of anionic surfactants as shown in Fig. 3.

Fig. 4 shows the powder X-ray diffraction spectra of assynthesized ZSM-5 on Kapok fiber. The XRD patterns agree with those found in the literature ${ }^{21}$. The X-ray patterns of ZSM5 do not change with silicon content indicating that the structure is unchanged even for silicalite. Fig. 5 shows the TG-DTA diagram of Kapok-ZSM-5. The exothermic reaction occurring at $420^{\circ} \mathrm{C}$ is the decomposition of template, TPABr. The ZSM5 framework contains two intersecting channel systems such 

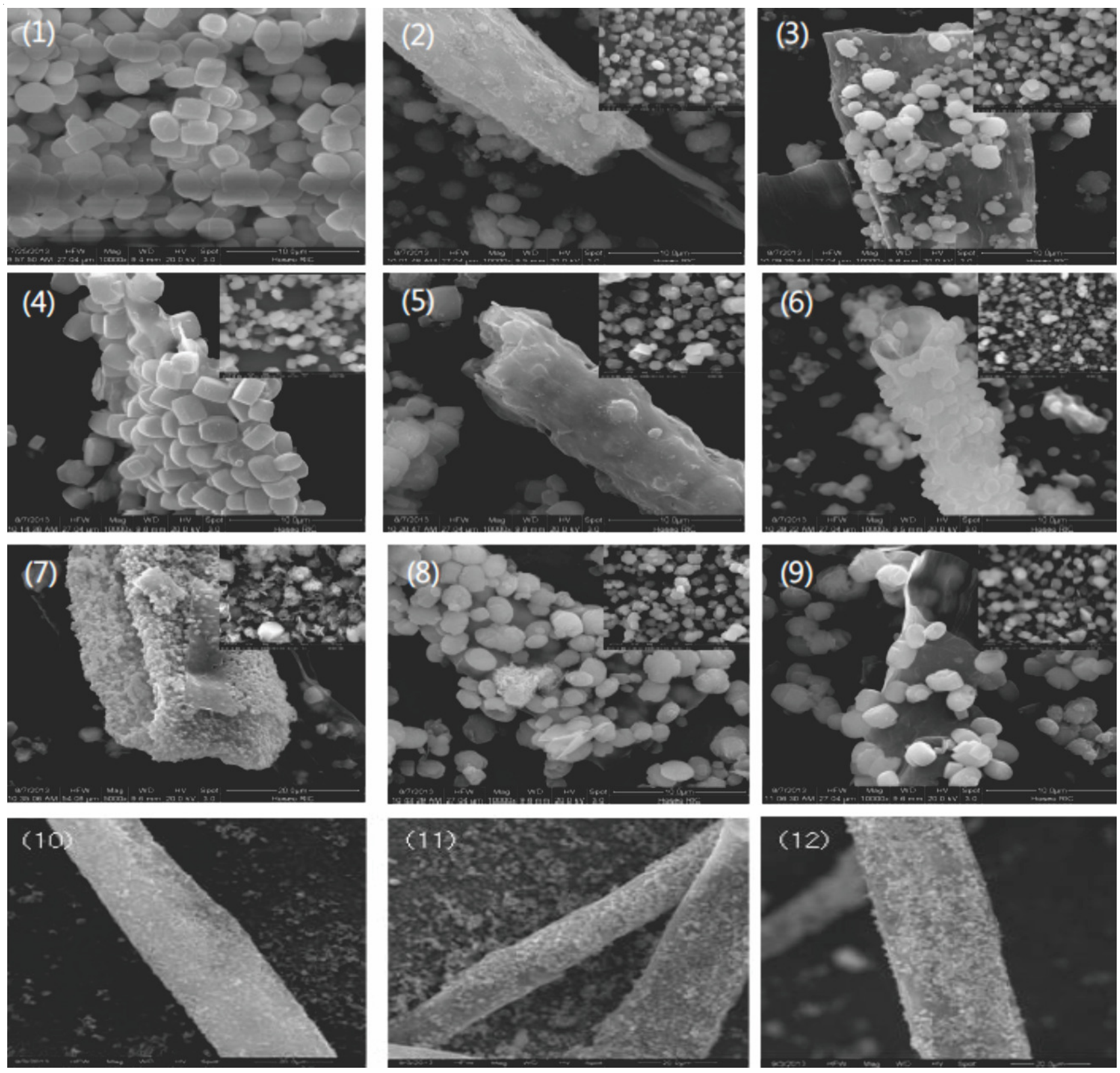

Fig. 3. SEM images of Kapok-ZSM-5 composites

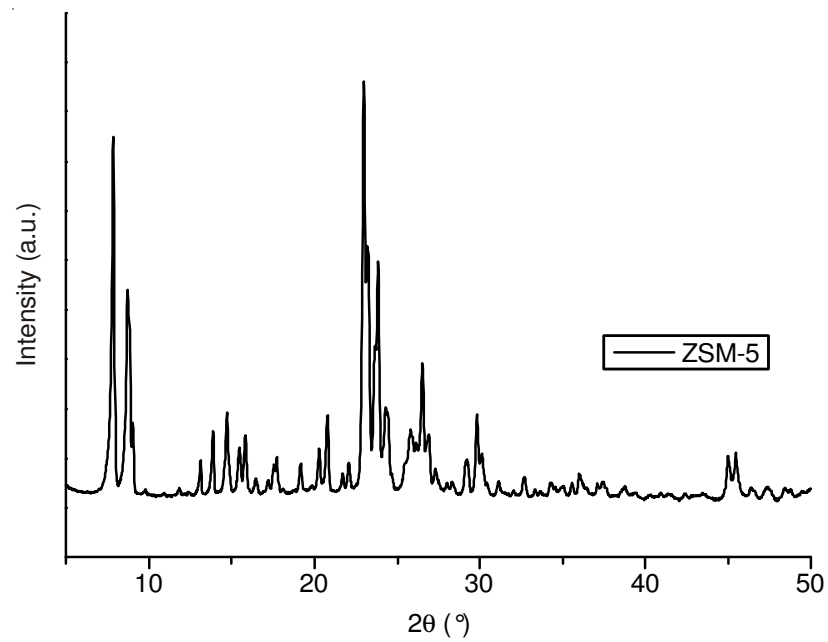

Fig. 4. XRD spectrum of Kapok-ZSM-5 composite (sample \#12)

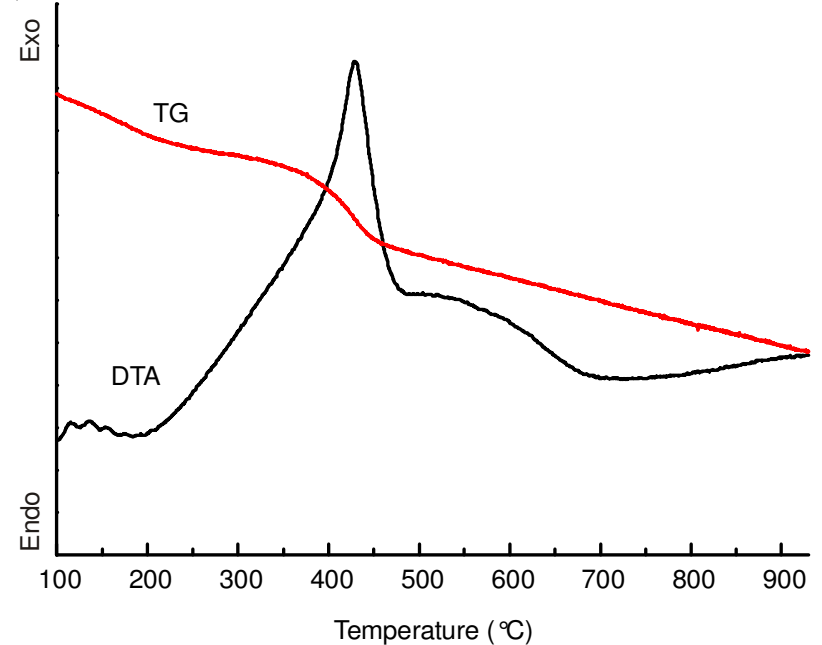

Fig. 5. TG-DTA diagram of Kapok-ZSM-5 composite (sample \#12) 
as straight and sinusoidal can be formed by the calcination of template, TPABr. The straight channels along the $\mathrm{b}$ direction are $5.4 \AA \times 5.6 \AA$ and the channels are $5.1 \times 5.5 \AA^{21}$.

Fig. 6 shows the FTIR spectra of ZSM-5 anchored Kapok. The absorption band at $1740 \mathrm{~cm}^{-1}$ is assigned to carbonyl $(\mathrm{C}=\mathrm{O})$ group of Kapok based on the chemical characterization. Kapok fiber contain acetyl groups up to $13 \%$. The band is decreased considerably after Kapok-ZSM-5 composites form. Three strong absorption bands at 1220, 1115 and $795 \mathrm{~cm}^{-1}$ are observed at ZSM-5-Kapok composite. The bands at 1115 and $1220 \mathrm{~cm}^{-1}$ are the absorption by asymmetric stretching of $\mathrm{Si}-\mathrm{O}$ bonds ${ }^{22,23}$. The band at $795 \mathrm{~cm}^{-1}$ is the character of ring structured $\mathrm{Si}-\mathrm{O}$ absorption band of zeolite and suggests a novel configuration of linked tetrahedral at three-dimensional framework structure.

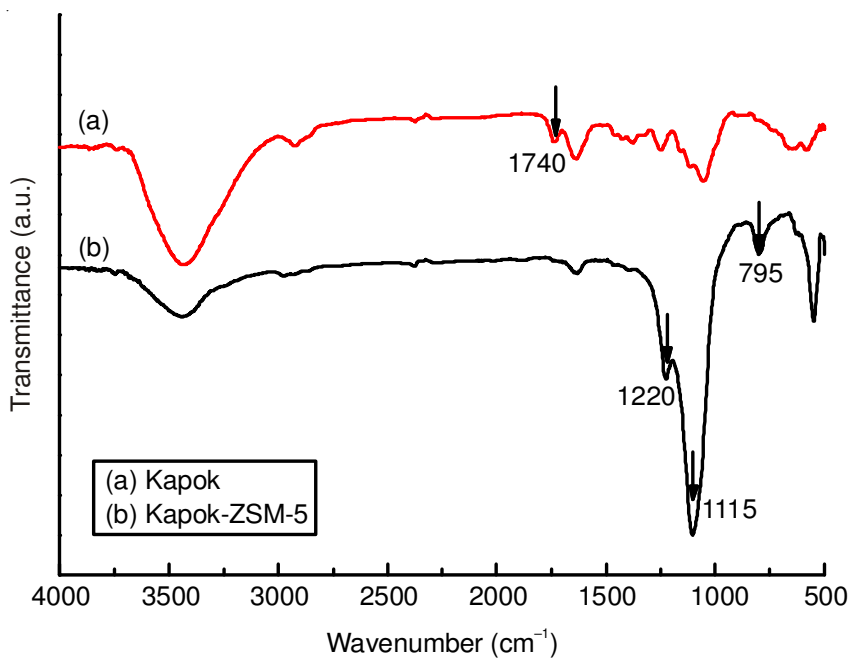

Fig. 6. FTIR spectrum of Kapok-ZSM-5 composite (sample \#12)

\section{Conclusion}

The hollow Kapok fibers were applied as a template in the hydrothermal reaction for the synthesis of Kapok-ZSM-5 composites. Most of the ZSM-5 materials were anchored on the surface of Kapok that suggests formation of ZSM-5 on Kapok fiber seems favorable at the treatment of anionic surfactants. The Kapok-ZSM-5 composites were confirmed and characterized by SEM, XRD, TG-DTA and FTIR analysis.

\section{ACKNOWLEDGEMENTS}

The authors acknowledged the financial support from the R\&D Convergence Program of MSIP (Ministry of Science, ICT and Future Planning) and ISTK (Korea Research Council for Industrial Science and Technology) of Republic of Korea (Grant B551179-12-07-00).

\section{REFERENCES}

1. C.T. Kresge, M.E. Leonowicz, W.J. Roth, J.C. Vartuli and J.S. Beck, Nature, 359, 710 (1992).

2. D. Zhao, J. Feng, Q. Huo, N. Melosh, G.H. Fredrickson, B.F. Chmelka and G.D. Stucky, Science, 279, 548 (1998).

3. G. Stucky, Y. Sakamoto, M. Kaneda, O. Terasaki, D.Y. Zhao, J.M. Kim, H.J. Shin and R. Ryoo, Nature, 408, 449 (2000).

4. S.B. Yoon, K. Sohn, J.Y. Kim, C.-H. Shin, J.-S. Yu and T. Hyeon, Adv. Mater., 14, 19 (2002).

5. S.B. Yoon, J.-Y. Kim, J.H. Kim, Y.J. Park, K.R. Yoon, S.-K. Park and J.-S. Yu, J. Mater. Chem., 17, 1758 (2007).

6. W. Zhang, Z. Huang, Z. Guo, C. Li and F. Kang, Mater. Lett., 64, 1868 (2010).

7. Y. Xia, B. Gates, Y. Yin and Y. Lu, Adv. Mater., 12, 693 (2000).

8. D. Cao, P. Feng and J. Wu, Nano Lett., 4, 1489 (2004).

9. D.W. Breck, Zeolite Molecular Sieves; Wiley: New York, Ch.1-7 (1974).

10. R. Szostak, Molecular Sieves: Principles of Synthesis and Identification; Van Nostrand Reinhold: New York, Ch. 1 and 2 (1989).

11. A. Dyer, An Introduction to Zeolite Molecular Sieves, Wiley: New York (1988).

12. S. Bhatia, Zeolite Catalysis: Principles and Application; CRC: Boca Raton, FL, Ch. 1-5 and 10 (1996).

13. J.P. Kim, I.-H. Cho, I.-T. Kim, C.-U. Kim, N.H. Heo and S.-H. Suh, Rev. Roum. Chim., 51, 1121 (2006).

14. S. Galdiero, A. Falanga, M. Vitiello, M. Cantisani, V. Marra and M. Galdiero, Molecules, 16, 8894 (2011).

15. S.N. Luoma, Y.B. Ho and G.W. Bryan, Mar. Pollut. Bull., 31, 44 (1995).

16. J.V. Rogers, C.V. Parkinson, Y.W. Choi, J.L. Speshock and S.M. Hussain, Nanoscale Res. Lett., 3, 129 (2008).

17. N.R. Panyala, E.M.P. Mendez and J. Havel, J. Appl. Biomed., 6, 117 (2008).

18. J.S. Lee, Y.-J. Lee, E.L. Tae, Y.S. Park and K.B. Yoon, Science, 301, 818 (2003).

19. R. Malkapuram, V. Kumar and Y.S. Negi, Reinf. Plast. Comp., 28, 1169 (2009).

20. X.Y. Zhang, C. Duan, N. Zhao, H. Xiao, M. Shi, X. Zhang and J. Xu, Chinese J. Polym. Sci., 28, 841 (2010).

21. S.-K. Park, V. Kurshev, Z. Luan, C. Wee Lee and L. Kevan, Micropor. Mesopor. Mater., 38, 255 (2000).

22. T.-T. Lim and X. Huang, Ind. Crops Prod., 26, 125 (2007).

23. H.J. Kim, C.H. Kwak, T.S. Suh and S.S. Suhr, Hwahak Konghak, 40, 377 (2000) 